\title{
FRAUD RISK MANAGEMENT FROM THE PERSPECTIVE OF CFEBT RISK TRIANGLE OF ACCOUNTING ERRORS AND FRAUDS
}

\begin{abstract}
Zita Drábková ${ }^{1}$
'Department of Accounting and Finances, Faculty of Economics, University of South Bohemia in České Budějovice, Studentská 13, 37005 České Budějovice, Czech Republic

To cite this article: DRÁBKOVÁ ZITA. 2018. Fraud Risk Management from the Perspective of CFEBT Risk Triangle of Accounting Errors and Frauds. Acta Universitatis Agriculturae et Silviculturae Mendelianae Brunensis, 66(5): 1261-1266.
\end{abstract}

To link to this article: https://doi.org/10.11118/actaun201866051261

\begin{abstract}
The objective of the present contribution is to evaluate the risk of the impact of accounting errors and frauds on reported accounting records on the basis of the CFEBT risk triangle of accounting errors and frauds. The analysis is conducted in the framework of a case study that examines a selected accounting unit predominantly operating in trade, with respect to financial statements reported during the years 2011-2015. The evaluation of the risk of impacts of accounting errors and frauds forms a part of one of the three vertices of the CFEBT risk triangle. The contribution presents results of the CFEBT approach at three levels of the M-score and analyses significant discrepancies between the generation of earnings and increase in cash flow during the observed periods. The CFEBT risk triangle was designed as a tool for detection, evaluation and management of the risk of accounting errors and frauds in circumstances of the Czech accounting standards and International Financial Reporting Standards (IFRS). The essential aim of the triangle is to reduce information asymmetry between authors and users of accounting records, or, in other words, to increase the quality of available information with respect to decision-making on the basis of available accounting information.
\end{abstract}

Keywords: CFEBT risk triangle of accounting errors and frauds, fraud risk management, creative accounting

\section{INTRODUCTION}

The highest principle of accounting is a "true and fair view," also described as a faithful view (faithful presentation). Beside the conscientious approach to the management and recognition of values along with the responsibility for selecting the correct method and processing of objective data, there exists "creative accounting", characterized by efforts to adjust economic transactions or accounting treatment of such transactions to intentions of a certain group of users of financial statements. In addition to valuation, economic transactions in the sense of a negative creative management may be illustrated by an example of accelerated sale of assets at low prices, without creating an adjustment, a situation that leads to corporate "tunnelling". Similar fictitious cases of sale and purchase and other non-transparent operations are reported as closing balances in accounting records. An intentional distortion of data in accounting as such, for gaining certain advantages, can be done in fact in all balance sheet items. However, such distortion of facts may lead to frauds that constitute intentional crimes punishable by sanctions under the Penal Code. But how can fraudulent intents of employees or management be uncovered? Detecting a fraudulent intent to gain unjust and illegal benefit is still "hard to crack." 
By an analysis of impacts of the risk of accounting errors and frauds, which is a part of the designed CFEBT anti-fraud triangle, the contribution aims at evaluating the risk of accounting errors and frauds, using an example of a selected accounting unit.

\section{MATERIALS AND METHODS}

Accounting records represent a significant source of information for users of financial statements, i.e. owners, company management, persons in charge of administration and management, potential investors, the State, creditors, customers and the public. On the one hand, users who use accounting records as the main source of information require an excellent quality of records, but on the other hand, we cannot ignore authors' various influences and motivations which affect the contents of individual record components. As regards the information asymmetry at work between authors and users of records, tools and options must be sought to reduce such information asymmetry or to identify risks of reliability of presented accounting records (Drábková, 2017).

Results of a Romanian research showed that more than a half of managers included in the sample had a tendency to change accounting principles that contribute considerably to the corporate image, and that there was a certain aversion to risks in relation to managers (Balaciu et al., 2014).

Prevention and detection of accounting frauds is also examined in Steve Dawson's publication. Steve Dawson presents the six elements of an effective anti-fraud programme-fraud risk assessment, control activities, information, communication, anti-fraud environment and monitoring (Dawson, 2015). Every year, departments engaged in investigation of corporate frauds receive dozens of reports of accusations of potential frauds. The need to discover a method for detection of risks of frauds with the aim of a fast solution is mentioned by a wide array of publications and research papers, such as (Caplan, 1994; Bloomfield, 1995). Moreover, results of research into a large telecommunication company imply that technical checks detect a mere one third of cases of frauds. More complex frauds are detected by a number of technical and social-technical checks both from the inside and outside of companies (Goode and Lacey, 2011). The main methods (strategies) with respect to creative accounting and accounting frauds were selected for an analysis of the impact of creative accounting techniques by the M-score CFEBT model. These selected techniques affected the true and fair view of accounting during accounting periods (Drábková, 2013; Drábková, 2015). Based on results of a previous research into information capacity of accounting and testing of the M-score of CFEBT model in a number of case studies in the context of Czech accounting standards and IFRS, a complex tool was designed for management the risk of accounting errors and frauds, in the form of a risk triangle of accounting errors and frauds, including analyses of three basic risk areas (vertices) of accounting errors and frauds (Drábková, 2017).

Reduced information asymmetry for users of accounting records may have significant impacts on their decision-making. The publication recommends a preventive detection of accounting errors, including uncovering the causes thereof (Wuerges and Borba, 2014).

Specific recommendations for the management to introduce internal auditing and set up different organizational internal controls for preventing frauds of financial statements were published as a result of a case study conducted in a construction company and construction industry (Horvat and Lipicnik, 2016). A proposal for a method for determining the probability of veracity of financial statements as a tool for distinguishing between fraudulent and truthful reports was published by authors Purda a Skillicorn (Purda and Skillicorn, 2015). Moreover, manipulation of accounting is rooted in attempts at tax evasion or money laundering. Results of frauds in the area of export are presented within the "Deep Learning" model, which classifies Brazilian producers as regards the options of committing frauds during export activities. According to the publication, this model was able to uncover certain anomalies, such as money laundering (Paula et al., 2016).

The analysis is concerned with tested periods for a selected accounting unit for available data drawn from 5 accounting periods, i.e. The years 2011-2015. The selected sample consists of accounting units of small companies the average number of employees of which is greater than 10 and does not exceed 50. The analysis makes use of reported data of financial statements of companies included in the database Albertina Gold Edition. The triangle of the risk of accounting errors and frauds works with the parameter of median value of the set and uses specific tools for risk management, which are set up based on results of a data analysis of a selected sample of comparable accounting units. These tools make it possible to specify the risk management with respect to requirements of a user who makes decisions on the basis of reported accounting data. This contribution examines only one of the three vertices of the risk triangle, i.e. The risk of impacts of accounting errors and frauds. Subsequently, the analysis of the risk of impacts proceeds to calculate the M-score of CFEBT model on its three levels, or, as the case may be, a test of risk of impacts of accounting errors and frauds on reported financial statements.

The calculation of the CFEBT score is based on the hypothesis that upon the observance of changes of cash flows net of taxes and generated earnings (CFEBT) before taxes, for five accounting periods as a minimum, changes have a tendency to yield similar results. The M-score was designed on the first level as an analytical test, which is proceeded by a detailed analysis of non-monetary expenses and 
revenues in a modified calculation of the second M-score level. To achieve a complex overview of the relations, a calculation of the third M-score level is included, which monitors the influence of relations of generated outputs of cash flow and CFEBT in the operational area

A single accounting unit was selected in order to present a detailed analysis in the case study, and for this accounting unit, the first level of M-score was determined above the established level of materiality, and a detailed analysis was conducted to ascertain the risk causes and impacts of manipulation of financial statements with respect to accounting errors and frauds beyond a true and fair view of accounting.

The backbone of the analysis is the CFEBT model, which was designed for the individual levels of the analysis of detailed interconnections between financial statements:

First level of M-score of CFEBT model is defined as follows:

$C F E B T=\frac{\sum_{\mathrm{t}=1}^{\mathrm{n}} \mathrm{CF}_{\mathrm{t}}-\sum_{\mathrm{t}=1}^{\mathrm{n}} \mathrm{EBT}_{\mathrm{t}}}{\sum_{\mathrm{t}=1}^{\mathrm{n}} \mathrm{EBT}_{\mathrm{t}}} \times 100$

Where:

CF - Total increase or decrease in cash flow before tax during the observed period $t$.

EBT - Earnings before tax, generated during the observed period.

If $C F E B T \geq$ materiality, a detailed test of links of impacts has to follow in the second and third levels of M-score. (Drábková, 2015)

The second level of M-score of CFEBT model (modified CFEBT score) is in compliance with the determined hypothesis as to the relation between the generation of cash flow and earnings. On this level, the generated funds and monetary equivalents for the observed period are modified by changes of balances of assets and liabilities, which represent potential additions or losses of funds. The sum of EBT generated during the observed period is modified by costs that are reported as non-monetary costs:

CFEBTm $=\frac{\sum_{\mathrm{t}=1}^{\mathrm{n}} \mathrm{CFm}_{\mathrm{t}}-\sum_{\mathrm{t}=1}^{\mathrm{n}} \mathrm{EBTm}_{\mathrm{t}}}{\sum_{\mathrm{t}=1}^{\mathrm{n}} \mathrm{EBTm}_{\mathrm{t}}} \times 100$

Where:

CFm - Increase in cash flow before tax in the observed period, modified by reported future cash in- and out-flows.

EBTm - Earnings before tax generated during the observed period, modified by non-monetary expenses.

The third level of M-score of CFEBT model expresses the proportion of the operating cash flow generated in the observed period and the modified earnings for the observed accounting period. In percentage terms, this is a proportion of the generated cash from operating activities to the generating earnings, which includes only costs and only the expenses and revenues that are directly converted to cash flow during the current or future accounting periods:

CFEBTom $=\frac{\sum_{\mathrm{t}=1}^{\mathrm{n}} \text { CFom }_{\mathrm{t}}-\sum_{\mathrm{t}=1}^{\mathrm{n}} \text { EBTm }_{\mathrm{t}}}{\sum_{\mathrm{t}=1}^{\mathrm{n}} \text { EBTm }_{\mathrm{t}}} \times 100$

Where:

$\mathrm{CF}_{\text {om }}$ - increase in operative cash flow before taxes in the analysed period.

$\mathrm{EBT}_{\mathrm{m}}$ - earnings before taxes gained for the analysed period modified by non-monetary expenses.

\section{RESULTS}

The contribution is concerned with the detection and evaluation of impacts of accounting errors and frauds for a selected accounting unit. This risk area is examined for the identification of risk of manipulation of accounting records using the CFEBT model on all of its three levels.

The first level of CFEBT calculates the M-score in order to determine the consistency between EBT and changes in funds and cash equivalents (cash). The second level of M-score modifies EBT and a change of CF by undervalued or overvalued items based on non-cash costs (revenues) and expenses (income) that are not included in EBT. The third level represents M-score of operating $\mathrm{CF}$ and modified EBT. For the selected vertex of the risk of impacts of accounting errors and frauds within the CFEBT risk triangle, the backbone is the calculation of M-score for the first, second and third levels. Based on the comparison of individual percentage values of the score, the impacts of CF and EBT may be evaluation for a longer period of time (at least 5 accounting periods).

The calculation of CFEBT will enable the user of financial statements to complete his/her view of accounting records by interconnections between cash flow and earnings on various levels. The first level of M-score functions as an analytical test that provides the decision-maker (user) with information as to the manner the accounting unit manages to transform the generated earnings into the generation of cash flow during at least 5 accounting periods. Where the first level of M-score exceeds the materiality level (10\% materiality is considered in this case), interconnections of impacts on accounting records are examined in form of a detailed test of the second level of the modified M-score.

The second level of the modified M-score "straightens" CF and EBT in an optimal transformation of earnings before tax into a change of cash flow. In addition, the decision-maker is provided information about significance of those accounting items that contribute to a change of EBT. The modified score should be reduced to an acceptable value of 
I: CFEBT M-score for the years 2011-2015

\begin{tabular}{lccc}
\hline $\begin{array}{c}\text { Analysis of risk of impacts of accounting } \\
\text { errors and frauds }-\mathbf{1}^{\text {st }}, \mathbf{2}^{\text {nd }}, \mathbf{3}^{\text {rd }} \text { levels of CFEBT }\end{array}$ & $\mathbf{1}^{\text {st }}$ level of $\mathbf{M}$-score & $\mathbf{2}^{\text {nd }}$ level of $\mathbf{M}$-score & $\mathbf{3}^{\text {rd }}$ level of M-score \\
\hline Taxable entity & Basic & Modified & M-operative \\
M-score & -59 & 13 & -2 \\
CF in TCZK & $-1,858$ & 24,674 & 21,456 \\
\hline $\mathbf{\Sigma}$ EBT in TCZK & $-4,478$ & 21,837 & 21,837 \\
\hline
\end{tabular}

*an increase in cash flow of reviewed accounting periods in thousands.

II: Modification items of 2nd level of M-score of CFEBT model for 2011-2015

\begin{tabular}{|c|c|c|c|}
\hline Item no. & $\begin{array}{c}\text { Description of item } \\
\text { (modification, informative) }\end{array}$ & $\mathrm{n}$ in TCZK & $\begin{array}{l}\text { n/EBT } \\
\text { in } \%\end{array}$ \\
\hline 1 & Receivables - 1 , from members & 0 & 0 \\
\hline 2 & Receivables -2 , from controlled and managed entities & 0 & 0 \\
\hline 3 & Receivables -3 , from accounting units with substantial influence & 0 & 0 \\
\hline 4 & Receivables -4 , trade receivables & -19372 & 433 \\
\hline 5 & Receivables -5 , from institutions & -11 & 0 \\
\hline 6 & Receivables -6 , other receivables & 6 & 0 \\
\hline 7 & Estimated accrued revenues & 118 & -3 \\
\hline 8 & Advance payments provided & 0 & 0 \\
\hline 9 & Inventory & 3022 & -67 \\
\hline 10 & Tangible fixed assets & -5215 & 116 \\
\hline 11 & Intangible fixed assets & -78 & 2 \\
\hline 12 & Long-term financial assets & 0 & 0 \\
\hline 13 & Payables to members & 0 & 0 \\
\hline 14 & Payables to controlled and managed persons & 0 & 0 \\
\hline 15 & Payables to accounting units under substantial influence & 0 & 0 \\
\hline 16 & Trade payables & 132 & -3 \\
\hline 17 & Advance payments received & 186 & -4 \\
\hline 18 & Payables to employees (institutions) & -855 & 19 \\
\hline 19 & Other payables & -99 & 2 \\
\hline 20 & Estimated accrued expenses & 18 & 0 \\
\hline 21 & Payables from notes and debentures & 0 & 0 \\
\hline 22 & Credits and loans received & 0 & 0 \\
\hline 23 & Depreciation & 25015 & -559 \\
\hline 24 & Adjustments & 0 & 0 \\
\hline 25 & Reserves & 1300 & -29 \\
\hline 26 & Gains or losses from acquired property in assets & 0 & 0 \\
\hline 27 & Gains or losses from revaluation of assets and liabilities & 0 & 0 \\
\hline 28 & Gains or losses from capital interest & 0 & 0 \\
\hline 29 & Gains or losses from revaluation in transformations & 0 & 0 \\
\hline 30 & Receivables from adjusted registered capital & 0 & 0 \\
\hline 31 & Accrued revenues & -818 & 18 \\
\hline 32 & Deferred expenses & 7 & 0 \\
\hline 33 & Equity capital & -27219 & 608 \\
\hline 34 & Total revenues from assets and material & 479 & -11 \\
\hline 35 & Total expenses on sale of assets and material & 98 & -2 \\
\hline
\end{tabular}

* EBT and CF non-cash and informative items: changes in values over the reviewed period

** items nos.1-22 - items for modification of CFm, nos. 23-25 - items for modification of EBTm, nos. 26-33 - informative items, nos. 34-35 - operative items for calculation of CFEBTmo 
the stated significance (materiality) in order to reduce the risk of accounting errors and frauds.

Consequently, the third level of M-score computes the ratio of operating cash flow and modified EBT, which provides information as to whether the selected accounting unit is able to effectively transform the operating costs and revenues into the operating cash flow within a monitored period (five years as a minimum), again after a tax aspect of income tax has been excluded.

In the detailed analysis of an impact risk of accounting errors and frauds, the selected accounting unit generated the following results of the M-score for monitored accounting periods of 2011-2015 (first level is significantly above the materiality threshold stated at 10\%).

Tab. I shows that the first M-score level of CFEBT is calculated at $-59 \%$. This value highly above the materiality threshold represents a significant discontinuity between cash flow generation and earnings before tax for the monitored period from the first through the fifth years for the selected accounting unit. This negative value specifies that the earnings achieved by the selected accounting unit are significantly higher than the generated cash flow

Tab. II shows individual modification and informative items, including their percentage proportion to EBT. These data are important for the final evaluation of the risk of causes and impacts of accounting errors and frauds.

In the detailed testing of the second M-score level, the first M-score level was reduced from $-59 \%$ to $13 \%$ (the "minus" sign signifies the discrepancy between the incurred change of cash flow and EBT), see Tab. I. Nevertheless, the M-score continues to show a value higher than the considered materiality. The third level of the M-score calculation presented in Tab. I computes a ratio of the generated operating cash flow and EBT after modification by costs that are not transformed into expenses. With respect to the fact that the operative M-score was calculated at $-2 \%$, the interconnections between impacts of EBT and cash flow may be interpreted as an inconsistency found outside the operating area, or, more specifically, the inconsistency of excess of the generation of cash flow over EBT is caused in the financial or investment area.

For the sake of a complex evaluation of the risk of accounting errors and frauds, the analysis conducted might be supplemented by the risk analysis using the other two vertices of the CFEBT risk triangle. The risk of causes is detected on the basis of selected 7 financial indicators based on the interconnection between EBT and cash flow and selected accounting items in a set of similar accounting unit for the individual observed periods.

Subsequently, a complex analysis is able to interconnect the area of causes of accounting errors and frauds with the impacts thereof. Based on the overall analysis of interconnections and discrepancies, it is then possible to evaluate the essence of inconsistency between the generation of cash flow and EBT for the observed period 2011-2015.

\section{DISCUSSION}

We elaborate the results of causes and impacts of accounting errors and frauds in small entity which

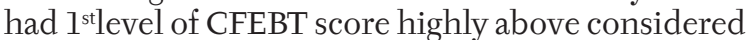
materiality.

Previous research carried out by comparison of the CFEBT approach with results of evaluation of selected bankruptcy models (Drábková, 2015) and models of detection of risks of manipulation of accounting records (Drábková, 2017) confirmed the efficiency of the complex CFEBT approach, which is based on interconnections between reported accounting information in the context of their economic substance. Despite the efficiency of individual detection models, it may be assumed that the focus of these models is placed on selected techniques of creative accounting and lack in complexity of the development of information reported in time and interconnections.

The analysis of important modification items revealed that the generation of accounting reserves increased by $29 \%$ (proportion to EBT), or, rather, costs increased during the observed period 2011-2015. The selected accounting unit maintains its accounting in accordance with Czech accounting standards, where accounting reserves for future liabilities are always expensed at the origin, as a consequence of which the negative financial performance increased during 2011-2015, or EBT decreased in 29\% proportion to EBT during this period.

In addition, the observed period saw a significant reduction of reported trade receivables - decrease by $433 \%$ to EBT and increase of stock by $67 \%$ proportion to EBT. It may be stated on the basis of the calculation of these proportions that changes in receivables and stock had no adequate impact on cash flow.

For users of accounting records of the analysed accounting unit, the analysis conducted detected no increased risk of distortion of accounting records caused by accounting errors or frauds. The analysis of interconnections between reported accounting information implied certain risk areas from the perspective of an economic substance (information capability) of accounting records with respect to receivables. These findings may be inspiring for management members, internal auditors, owners and other users of accounting records. Results of the CFEBT risk triangle of accounting errors and frauds may be used for increasing the quality of a decision-making process based on reported accounting information, especially with respect to external users of accounting records, for management members also as a tool for increasing the efficacy of the internal control system or for setting up control processes of managerial accounting, which draws upon financial accounting reports. 


\section{CONCLUSION}

In general, the accounting unit does not present risk in terms of the detection of risk of causes and impacts of accounting errors in circumstances of the Czech accounting standards. However, the specific conclusions of the analysis can be used for reducing information asymmetry and for decision-making of external and internal users of accounting records in line with the level of their access to accounting information.

Specifically and by way of example, auditors can focus on examining the adequacy of the generation and drawdown of reserves and adjustments in relation to the suitability of the amount of dividend payout to shareholders, and evaluate whether certain creative accounting methods (such as "Big Bath" - one of the aggressive accounting methods) have been applied on purpose in order to deepen a loss during a certain selected period and then to increase earnings sharply, in particular with the intention of paying inadequate dividends for profitable accounting periods. Moreover, the results of the risk analysis may lead to similar questions asked by potential investors and owners. Effective management considered, these identified areas may improve the quality of accounting management and the information capability thereof with respect to the evaluation of financial health of the given business corporation. The other vertices (risk factors) of the designed CFEBT risk triangle are intended for testing the risk of the internal control system and the risk of causes (motives) of occurrence of accounting errors and frauds.

We believe that the CFEBT risk triangle may be used on various decision-making levels as effected by users of financial statements to enable these users to decide. In addition, the evaluation of this complex tool makes it possible to reduce information asymmetry between authors and users of reported accounting outputs to allow these users to make decisions of best quality on the basis of accounting data available to them.

Acknowledgements

This paper was supported by the University of South Bohemia, Faculty of Economics [no. IGS05C1].

\section{REFERENCES}

BALACIU, D. E., BOGDAN, V., FELEAGA, L. et al. 2014. Accounting Outside the Box. An Introspective Study on the "Colorful" Mind of Managers Reflectec in Creative Accounting. Journal of Accounting and Management Information Systems, 13(4): 643-664.

BLOOMFIELD, R. 1995. Strategic Dependence and Inherent Risk Assessments. The Accounting Review, 70(1): 71-90.

CAPLAN, D. 1994. The Expectations Gap: Understanding Auditors' Efforts to Detect Fraud. Ph.D. Dissertation. USA: University of California at Berkeley.

DAWSON, S. 2015. Internal Control/Anti-Fraud Program Design for The Small Business. UK: John Wiley and Sons Ltd.

DRÁBKOVÁ, Z. 2013. The potential to reduce the risk of manipulation of financial statements using the identification models of creative accounting. Acta universitatis agriculturae et silviculturae Mendelianae Brunensis, 61(7): 2055-2063.

DRÁBKOVÁ, Z. 2015. Analysis of possibilities of detecting the manipulation of financial statements in terms of the IFRS and Czech accounting standards. Acta universitatis agriculturae et silviculturae Mendelianae Brunensis, 63(6): 1859-1866.

DRÁBKOVÁ, Z. 2017. Kreativní účetnictví a účetní podvody - Řízení rizika účetních chyb a podvodů. Praha, Česko: Wolters Kluwer.

GOODE, S. and LACEY, D. 2011. Detecting complex account fraud in the enterprise: The role of technical and non-technical controls. Decision Support Systems, 50(4): 702-714.

HORVAT, T. and LIPICNIK, M. 2016. Internal Audits of Frauds in Accounting Statements of a Construction Company. Strategic Management, 21(4): 29-36.

PAULA, E. L., LADEIRA, M., CARVALHO, R. N. et al. 2016. Deep Learning Anomaly Detection as Support Fraud Investigation in Brazilian Exports and Anti-Money Laundering. In: 15th Ieee International Conference on Machine Learning and Applications. IEEE, 18-20 December. California, USA, pp. 954-960.

PURDA, L. and SKILLICORN, D. 2015. Accounting Variables, Deception, and a Bag of Words: Assessing the Tools of Fraud Detection. Contemporary Accounting Research, 32(3): 1193-1223.

WUERGES, A. F. E. and BORBA, J. A. 2014. Accounting Fraud: an estimation of detection probability. Rbgn-Revista Brasileira De Gestao De Negocios, 16(52): 466-483. 